\title{
Vitamin D Levels in Pediatric Asthma: A Comparative Study
}

\author{
Fahad Aleem ${ }^{1}$, Yusra Iqbal ${ }^{2}$, Mohammed Asrar UI Huq Iqbal ${ }^{3}$, Sara Khan ${ }^{4}$ \\ ${ }^{1}$ Consultant,Department of Pulmonology, CARE Hospital, Hyderabad, ${ }^{2}$ Consultant, Department of Pulmonary Medicine, \\ Sitara Medical Center. Hyderabad, ${ }^{3}$ Consultant Pediatrician, Krishna Children's Hospital, Hyderabad, ${ }^{4}$ Observer, Department \\ of Pediatrics, Rainbow Hospitals, Hyderabad
}

Corresponding author: Dr Fahad Aleem, Consultant, Department of Pulmonology, CARE Hospital, Hyderabad, India

DOI: http://dx.doi.org/10.21276/ijcmsr.2019.4.2.7

How to cite this article: Fahad Aleem, Yusra Iqbal, Mohammed Asrar Ul Huq Iqbal, Sara Khan. Vitamin D levels in pediatric asthma: a comparative study. International Journal of Contemporary Medicine Surgery and Radiology. 2019;4(2):B31-B35.

\section{A B S T R A C T}

Introduction: Vitamin D is essential for growing children and its deficiency may have a catastrophic effect on growing child. Vitamin D deficiency is also reported to have an effect on immunity and inflammatory responses. Many authors have reported that there is increased incidence of recurrent respiratory tract infections and asthma in children having vitamin D deficiency. We undertook this prospective study to compare vitamin D status of children having asthma with healthy children and find out whether there is an association between vitamin D deficiency and childhood asthma.

Material and Methods: This was a prospective comparative study in which children between 5-13 years and having asthma were included as cases on the basis of a predefined inclusion and exclusion criteria. Age matched healthy children were enrolled in controlled group. Demographic details were noted and clinical examination was done in all the cases. Pulmonary function test, Sr Calcium, Sr Phosphorus, Sr alkaline phosphatase and $25(\mathrm{OH})$ vitamin D levels were estimated in all the cases. The FEV1\% and FEV1 to FVC ratio as well as $25(\mathrm{OH})$ vitamin D levels were compared in both the groups. Statistical analysis was done using SSPs v 18.0. P value less than 0.05 was taken as statistically significant.

Results: Out of total 60 children there were 42 (70\%) males and $18(30 \%)$ females with a M:F ratio of 1:0.42. The mean age of children in group A and Group B was found to be 8.4 +/- 2.04 years and 7.9 +/- 1.95 years respectively. Height, weight and $\mathrm{BMI}$ were found to be comparable in both the cases with no statistically significant difference. The comparison of FEV1\% and FEV1 to FVC ratio was found to be higher in control group as compared to children with asthma and the difference was statistically highly significant. Sr. $25(\mathrm{OH})$ cholecalciferol levels were found to be higher in healthy children as compared to children with asthma and the difference was found to be statistically significant $(P<0.0001)$.

Conclusion: Vitamin D deficiency is more common in children with bronchial asthma as compared to age matched healthy children.

Keywords: Bronchial Asthma, Children, $25(\mathrm{OH})$ Cholecalciferol, Pulmonary Function Tests.

\section{INTRODUCTION}

Vitamin D is the generic term used to denote metabolically active compounds such as cholecalciferol (Vitamin D3) and ergocalciferol (Vitamin D2). The major source of vitamin D is the synthesis of cholecalciferol in the skin from cholesterol on exposure to sunlight. ${ }^{1}$ Food items that are rich in vitamin $\mathrm{D}$ include fish, beef, cheese and egg yolk. Vitamin D has a major role in calcium and bone metabolism and its deficiency leads to rickets in growing children and osteomalacia in adults or older population. ${ }^{2}$ In addition to bone metabolism vitamin $\mathrm{D}$ is also essential for normal functioning of immune system of the body. The other important finding which has been a topic of immense interest amongst researchers is the role of vitamin $\mathrm{D}$ in the pathogenesis of asthma in childhood. ${ }^{3}$

It has been reported that vitamin D plays a crucial role in the proper growth and development in fetal lung growth and maturity. There are studies that suggest that maternal intake of vitamin D in appropriate doses is associated with decreased risk of recurrent respiratory tract infections and childhood asthma. In many children with steroid resistant asthma addition of vitamin D supplementation may increase the responsiveness to steroid in these patients. Vitamin D deficiency states are reported to be associated with increased risk of acute exacerbations of bronchial asthma. ${ }^{4}$

Many researchers have found that vitamin $\mathrm{D}$ has an inhibitory effect on Th17 response. Th17 cells are thought to have an important role in the etiopathogenesis of childhood asthma. ${ }^{5}$ Many researchers have reported the role of FoxP3 cells and TGF-Beta in the pathogenesis of asthma and these cytokines were found to correlate with serum 25 hydroxycholecalciferol levels. The genetics associated with vitamin $\mathrm{D}$ deficiency and childhood asthma is complex and the exact enteropathogenic mechanism of asthma in vitamin $\mathrm{D}$ deficiency is not known but the studies have pointed out towards involvement of Vitamin D Receptor (VDR) gene in pathogenesis of childhood asthma and vitamin deficiency states. $^{6}$

The effect of vitamin D deficiency on lungs is related 
to improper growth and development of lung tissue. Adequate Vitamin D levels are found to be associated with a significantly decreased risk of recurrent wheezing and asthma. ${ }^{7}$ Though many studies have favored the notion that vitamin $\mathrm{D}$ deficiency increases the risk of recurrent wheezing and eventually development of asthma in pediatric age group there are other studies which have failed to demonstrate the beneficial effect of vitamin $\mathrm{D}$ supplementation on prevention of childhood asthma. ${ }^{8}$ Similarly, the issue of antenatal vitamin D supplementation to pregnancy women for preventing development of asthma in children is the topic of intense debate amongst researchers and no unanimous guidelines exist in this regard. ${ }^{9}$

In pediatric age group vitamin $\mathrm{D}$ status of the patients can be determined by estimation of 25 hydroxycholecalciferol. In pediatric age group vitamin $\mathrm{D}$ sufficiency is said to be present if $25(\mathrm{OH})$ vitamin $\mathrm{D}$ levels are found to be more than $20 \mathrm{ng} / \mathrm{ml}$ whereas insufficient and deficiency is said to exist if the $25(\mathrm{OH})$ vitamin $\mathrm{D}$ levels are between 15-20 $\mathrm{ng} / \mathrm{ml}$ and less than $15 \mathrm{ng} / \mathrm{ml}$ respectively. ${ }^{10}$ We conducted this comparative study to determine Vitamin D status of 30 patients with childhood asthma and compared them with 30 healthy children.

\section{MATERIAL AND METHODS}

It was a case control study conducted in the pulmonology department of a tertiary care hospital situated in a metropolitan city. 30 Pediatric patients with bronchial asthma (As per GINA guidelines) ${ }^{11}$ were included in this study as cases on the basis of a predefined inclusion and exclusion criteria. 30

\begin{tabular}{|l|c|c|c|c|}
\hline \multirow{2}{*}{ Age Groups } & \multicolumn{2}{|c|}{ Group A } & \multicolumn{2}{c|}{ Group B } \\
\cline { 2 - 5 } & $\begin{array}{l}\text { No of } \\
\text { cases }\end{array}$ & Percentage & $\begin{array}{c}\text { No of } \\
\text { cases }\end{array}$ & Percentage \\
\hline 5-7 years & 8 & $26.67 \%$ & 9 & $30.00 \%$ \\
\hline $8-10$ years & 16 & $53.33 \%$ & 18 & $60.00 \%$ \\
\hline $11-13$ years & 6 & $20.00 \%$ & 3 & $10.00 \%$ \\
\hline Mean Age & $8.4+/-2.04$ years & \multicolumn{3}{c|}{$7.9+/-1.95$} \\
\hline $\mathrm{P}=0.56$ (Not Significant) \\
\hline
\end{tabular}

healthy children of comparable age group were enrolled as control group. informed written consent was obtained from parents or guardians of the children included in this study. Demographic details such as age, gender, address and socioeconomic status of all the children were noted. Past history and history of asthma in any family members was also noted. dietary history was asked in detail and noted. A through clinical examination was done in all the cases particularly with respect to finding out the clinical signs of presence of vitamin $\mathrm{D}$ deficiency such as widened wrists, frontal bossing, bow legs or rachitic rosary etc. systemic examination was also done in all the children and anyone found to be having any significant systemic illness was excluded from the study. All children underwent pulmonary function test. Laboratory investigations done in cases as well as controls included serum calcium, serum phosphorus, serum alkaline phosphatase and $25(\mathrm{OH})$ cholecalciferol.

The vitamin $\mathrm{D}$ status of the all children was determined and they were classified into vitamin D sufficient, insufficient, deficiency and severely deficient categories on the basis of 25 $(\mathrm{OH})$ cholecalciferol levels.

Demographic variables and vitamin D levels were compared between cases and control group. Statistical analysis was done using SSPE 16.0 software. P value less than 0.05 was taken as statistically significant.

\section{Inclusion Criteria}

Cases Group:

1. Children diagnosed to be having bronchial asthma as per GINA guidelines.

2. Informed consent obtained from parents or guardians.

3. Age between 5-13 years.

Control Group:

1. Age matched healthy children with no history asthma.

\section{Exclusion Criteria}

1. Parents or guardians refused consent.

2. Children with systemic illnesses.

\section{RESULTS}

In this study of vitamin $\mathrm{D}$ status of children with childhood asthma 30 children with asthma were included in Group A

\begin{tabular}{|l|c|c|c|c|c|}
\hline \multirow{2}{*}{ Parameters } & \multicolumn{2}{|c|}{ Group A } & \multicolumn{2}{c|}{ Group B } & Significance \\
\cline { 2 - 6 } & Mean & Std Deviation & Mean & 14.78 & $\begin{array}{c}0.172 \\
\text { (Not Significant) }\end{array}$ \\
\hline Height (cms) & 112.72 & 16.22 & 118.26 & 6.34 & 0.946 \\
Weight (Kg) & 24.12 & 4.98 & 24.02 & 6.78 & $\begin{array}{c}0.209 \\
\text { (Not Significant) }\end{array}$ \\
\hline BMI (Kg/m2) & 17.20 & 2.80 & 18.90 & & \\
\hline
\end{tabular}

\begin{tabular}{|l|c|c|c|c|c|}
\hline \multirow{2}{*}{ Pulmonary Function Test } & \multicolumn{2}{|c|}{ Group A } & \multicolumn{2}{c|}{ Group B } & Significance \\
\cline { 2 - 6 } & Mean & Std Deviation & Mean & Std Deviation & $\begin{array}{c}<0.0001 \\
\text { (Highly Significant) }\end{array}$ \\
\hline FEV1\% & 72.7 & 7.8 & 94.6 & 8.4 & $<0.0001$ \\
(Highly Significant)
\end{tabular}




\begin{tabular}{|l|c|c|c|c|l|}
\hline \multirow{2}{*}{ Parameters } & \multicolumn{2}{|c|}{ Group A } & \multicolumn{2}{|c|}{ Group B } & Significance \\
\cline { 2 - 6 } & Mean & Std Deviation & Mean & Std Deviation & \\
\hline Sr Calcium (mg/dl) & 9.72 & 8.2 & 9.80 & 6.8 & $\begin{array}{l}0.96 \\
\text { (Not Significant) }\end{array}$ \\
\hline Sr Phosphorus (mg/dl) & 5.14 & 0.5 & 5.10 & 0.7 & $\begin{array}{l}0.79 \\
\text { (Not Significant) }\end{array}$ \\
\hline Sr Alkaline Phosphatase (U/L) & 220.46 & 62.2 & 228 & 58.9 & $\begin{array}{l}0.63 \\
\text { (Not Significant) }\end{array}$ \\
\hline Sr. 25 (OH) cholecalciferol & 10.67 & 4.73 & 18.06 & 3.21 & $\begin{array}{l}<0.0001 \\
\text { (Highly Significant) }\end{array}$ \\
\hline
\end{tabular}

Table-4: Comparison of Sr Calcium, Sr Phosphorus, Alkaline phosphatase and $25(\mathrm{OH})$ cholecalciferol in both the groups.

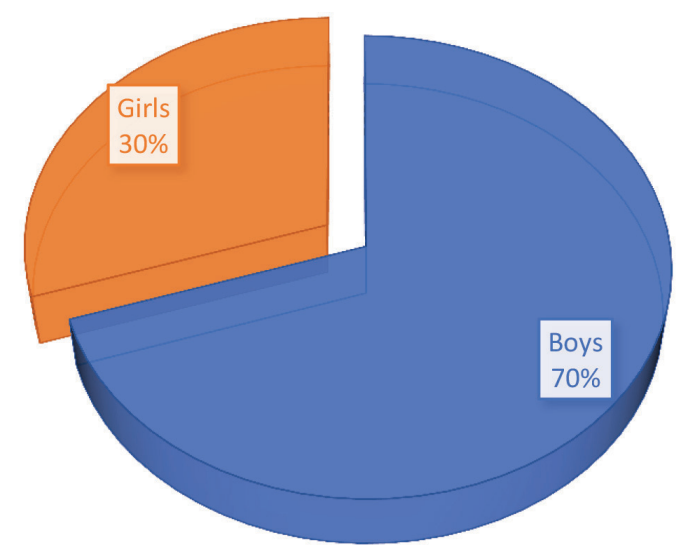

Figure-1: Gender Distribution of the studied cases.

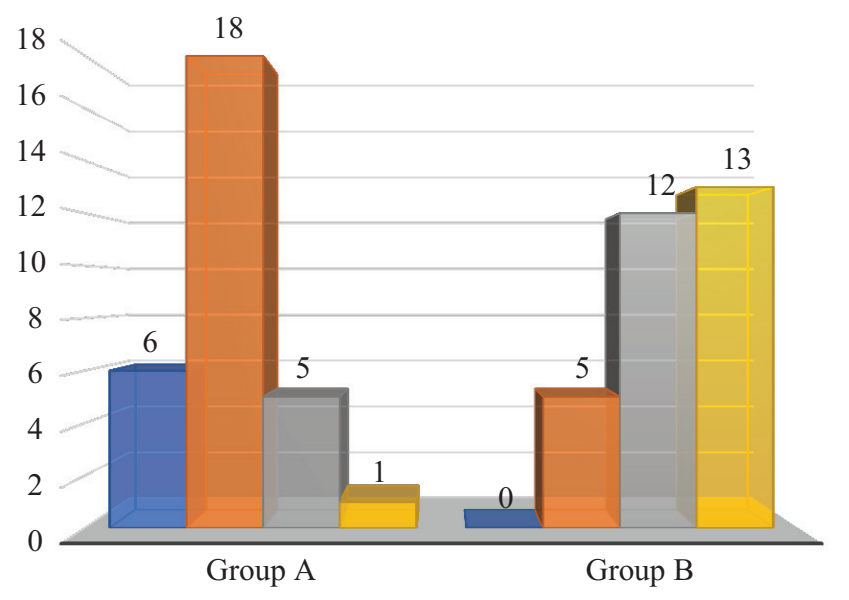

$\square$ Severe Deficiency $\square$ Deficiency $\square$ Insufficiency $\square$ Sufficiency

Figure-2: Vitamin D status in both the groups.

(cases) whereas healthy children were included in group B (controls). Out of the total 60 children there were 42 (70\%) males and 18 (30\%) females with a M:F ratio of $1: 0.42$ (graph-1).

The analysis of age groups of the studied cases showed that the most common age group in Group A as well as Group $B$ was $8-10$ years. The mean age of children in group $A$ and Group B was found to be $8.4+/-2.04$ years and $7.9+/-1.95$ years respectively. The age groups were comparable and there was no statistically significant difference in the age groups of Group A and Group B ( $\mathrm{P}=0.56)$ (table-1).

The analysis of weight and body mass index of the studied cases showed that mean height of the patients in Group A and Group B was $112.72+/-16.22 \mathrm{~kg}$ and $118.26+/-14.78$ $\mathrm{cms}$ respectively. The mean weight of the patients in group
A and group B was $24.12+/-4.98$ and $24.02+/-6.34 \mathrm{~kg}$ respectively. The analysis of BMI showed that mean BMI in group A and B was $17.20+/-2.80$ and $18.90+/-6.78$ $\mathrm{Kg} / \mathrm{m} 2$ respectively. The mean height,weight and BMI of the children in both the groups were found to be comparable and there was no statistically significant difference in both the groups (table-2).

Pulmonary function tests were done in all children in both the groups. FEV1\% and ratio of FEV1 to FVC was determined in all the cases. The mean FEV1\% in Group A and Group B was $72.7+/-7.8$ and $94.6+/-5.4$ respectively whereas ratio of FEV1/FVC was $69.8+/-8.4$ and $89.3+/-8.8$ in group A and group $\mathrm{B}$ respectively. The difference in $\mathrm{FEV} 1 \%$ and ratio of FEV1/FVC was found to be statistically highly significant $(\mathrm{P}<0.0001)($ table-3).

The analysis of serum calcium, serum phosphorus and serum alkaline phosphatase was done in all the cases. The mean serum calcium in cases and control group was found to be $9.72+/-8.2 \mathrm{mg} / \mathrm{dl}$ and $9.80+/-6.8 \mathrm{mg} / \mathrm{dl}$. Serum phosphorus was $220.46+/-62.2$ and $228+/-58.9 \mathrm{mg} / \mathrm{dl}$. Alkaline phosphatase was also found to be comparable. There was no statistically significant difference in sr calcium, sr phosphorus and Alkaline phosphatase values in both the groups. The analysis of levels of serum $25(\mathrm{OH})$ cholecalciferol showed that mean $\operatorname{Sr} 25(\mathrm{OH})$ cholecalciferol level was $10.67+/-$ 4.73 and $18.06+/-3.21$ respectively. $25(\mathrm{OH})$ vitamin $\mathrm{D} 3$ was found to be higher in patients of control group and the difference was found to be statistically significant $(\mathrm{P}<0.0001)$ (table-4).

The cases in both thegroups were divided into having sufficiency $(\geq 20 \mathrm{ng} / \mathrm{mL})$, insufficiency $(15-20 \mathrm{ng} / \mathrm{ml})$, deficiency $(\leq 15 \mathrm{ng} / \mathrm{mL})$ and severe deficiency $(\leq 5 \mathrm{ng} / \mathrm{mL})$ on the basis of vitamin D levels. There was no patient with severe deficiency in Group B where as in group A there were $6(20 \%)$ patients with severe deficiency. Similarly,incidence of deficiency was more in Group A (60\%) as compared to group B (16.66\%). Vitamin D insufficiency and sufficiency was seen in $5(16.66 \%)$ and $1(3.33 \%)$ patients in group A whereas in group B it was present in $12(30 \%)$ and 13 (33.33\%) patients respectively (figure-2).

\section{DISCUSSION}

Vitamin D is an essential factor for development of growing children. The common presentation of vitamin $\mathrm{D}$ deficiency in growing children is rickets which may present as widened epiphysis (particularly wrists), frontal bossing, delayed closure of sutures amongst many others. ${ }^{12}$ Many researchers 
have come up with the evidence that vitamin D not only is responsible for proper skeletal growth but also is important for intact immune system. Various studies have also found that children with childhood asthma are more likely to have vitamin $\mathrm{D}$ deficiency as compared to their healthy counter parts. ${ }^{13}$

We conducted this study to analyze vitamin $\mathrm{D}$ levels in pediatric patients with asthma and to compare it with vitamin $\mathrm{D}$ levels in healthy children. IN this study there were $42(70 \%)$ boys and 18 (30\%) girls with a M:F ratio of 1:0.42 The mean age of the children in cases and control group was found to be $8.4+/-2.04$ years and $7.9+/-1.95$ years respectively and the mean age was found to be comparable in both the groups. Similarly, height, weight and body mass index of the children in group A and Group B was found to be comparable and there was no statistically significant difference in these parameters in both the groups.

IN our study children in Group A (childhood asthma) were found to have lower levels of $25(\mathrm{OH})$ cholecalciferol as compared to healthy children and the difference was found to be statistically highly significant $(\mathrm{P}<0.0001)$.Many authors have suggested that vitamin $\mathrm{D}$ levels can be correlated with the severity of asthma and children with lower levels of vitamin $\mathrm{D}$ are expected to have a more severe asthma as compared to children with adequate vitamin D levels. Kranam $S$ et al conducted a cross sectional study of 60 children with asthma with a purpose to know the relationship between serum vitamin $\mathrm{D}$ levels and severity of asthma. ${ }^{14}$ The authors found that children with well controlled asthma had higher serum levels of $25(\mathrm{OH}) \mathrm{D}$ than children with partially controlled or uncontrolled asthma. On the basis of these findings the authors concluded that vitamin $\mathrm{D}$ deficiency is associated with exacerbations, decreased lung functions and severe disease. Similar correlation of severity of asthma and vitamin $\mathrm{D}$ levels have also been reported by the authors such as Pragalatha Ket $\mathrm{al}^{15}$ and Jat KRet al. ${ }^{16}$

As children with recurrent respiratory tract infections as well as children with asthma are found to have increased incidence of vitamin D deficiency many researchers have recommended that vitamin D supplementation should be given to children with these complaints. ${ }^{17}$ Riverin $\mathrm{BD}$ et al conducted a systematic review and meta-analysis to evaluate the efficacy and safety of vitamin D supplementation as a treatment or adjunct treatment for asthma. ${ }^{18}$ The authors found that There was a reduced risk of asthma exacerbations in children receiving vitamin D (low-quality; RR 0.41 , 95\% CI 0.27 to $0.63,3$ studies, $\mathrm{n}=378)$. On the basis of these findings the authors concluded that there exists evidence (although of low quality) to support vitamin $\mathrm{D}$ supplementation for the reduction of asthma exacerbations. It is important to emphasize that repeated acute exacerbations requiring hospitalization and long-term inhalational steroids may have detrimental effect on growth and development of growing children. Jolliffe DA et al in their review of seven studies (955 participants) found that Vitamin D supplementation reduced the rate of asthma exacerbations requiring treatment with systemic corticosteroids overall. Similar beneficial effects of vitamin D supplementation in children with asthma have been reported by the authors such as Kang Q et $\mathrm{al}^{19}$ and Yadav $\mathrm{M}$ et al. ${ }^{20}$

\section{CONCLUSION}

Vitamin D deficiency is more common in children with bronchial asthma as compared to age-matched healthy children. These children need appropriate supplementation of vitamin $\mathrm{D}$ in order to prevent repeated acute exacerbations requiring hospitalization and systemic corticosteroids.

\section{REFERENCES}

1. Wacker M, Holick MF. Sunlight and Vitamin D: A global perspective for health. Dermatoendocrinol. 2013;5(1):51-108.

2. Ohata Y,Ozono K. Updates on rickets and osteomalacia: guidelines for diagnosis of rickets and osteomalacia. Clin Calcium. 2013;23(10):1421-8.

3. Hall SC, Agrawal DK. Vitamin D and Bronchial Asthma: An Overview of Data From the Past 5 Years. Clin Ther. 2017;39(5):917-929.

4. Ali NS, Nanji K. A Review on the Role of Vitamin D in Asthma. Cureus. 2017;9(5):e1288.

5. Bantz SK, Zhu Z, Zheng T. The Role of Vitamin $\mathrm{D}$ in Pediatric Asthma. Ann Pediatr Child Health. 2015;3(1):1032.

6. Hou C, Zhu X, Chang X. Correlation of vitamin D receptor with bronchial asthma in children. Exp Ther Med. 2018;15(3):2773-2776.

7. Hibbs AM, Ross K, Kerns LA, Wagner C, Fuloria M, Groh-Wargo S, Zimmerman T,Minich N, Tatsuoka C. Effect of Vitamin D Supplementation on Recurrent Wheezingin Black Infants Who Were Born Preterm: The D-Wheeze Randomized Clinical Trial.JAMA. 2018;319(20):2086-2094.

8. Esfandiar N, Alaei F, Fallah S, Babaie D, Sedghi N. Vitamin D deficiency and its impact on asthma severity in asthmatic children. Ital J Pediatr. 2016;42(1):108.

9. Curtis EM, Moon RJ, Harvey NC, Cooper C. Maternal vitamin D supplementation during pregnancy. Br Med Bull. 2018;126(1):57-77.

10. Lee JY, So TY, Thackray J. A review on vitamin $\mathrm{d}$ deficiency treatment in pediatric patients. J Pediatr Pharmacol Ther. 2013;18(4):277-291.

11. Reddel HK, Bateman ED, Becker A, et al. A summary of the new GINA strategy: a roadmap to asthma control. Eur Respir J. 2015;46(3):622-639.

12. Sahay M, Sahay R. Rickets-vitamin D deficiency and dependency. Indian $\mathrm{J}$ Endocrinol Metab. 2012;16(2):164-176.

13. Manousaki D, Paternoster L, Standl M, Moffatt MF, Farrall M, Bouzigon E,Strachan DP, Demenais F, Lathrop M, Cookson WOCM, Richards JB. Vitamin D levelsand susceptibility to asthma, elevated immunoglobulin E levels, and atopicdermatitis: A Mendelian randomization study. PLoS Med. 2017 May 9;14(5)

14. Karanam S, Reddy S, Ramesh H. Vitamin D status in asthmatic children and its correlation to asthma control. Int J Contemp Pediatr 2018;5(2):520-5.

15. Pragalatha K, Gowdra A, Arathi, Ananya Sampath A. A clinical study to determine the relationship between serum vitamin $\mathrm{d}$ levels and severity of asthma. Int $\mathrm{J}$ 
Contemp Pediatr 2017;4(4):1397-1400.

16. Jat KR, Khairwa A. Vitamin D and asthma in children: A systematic review and meta-analysis of observational studies. Lung India. 2017;34(4):355-363.

17. Solidoro P, Bellocchia M, Aredano I, et al. Asthmatic Patients with Vitamin D Deficiency have Decreased Exacerbations after Vitamin Replacement. Nutrients. 2017;9(11):1234.

18. Riverin BD, Maguire JL, Li P. Vitamin D Supplementation for Childhood Asthma: A Systematic Review and Meta-Analysis. PLoS One. 2015 Aug 31;10(8): 28-31.

19. Kang Q, Zhang X, Liu S, Huang F. Correlation between the vitamin $\mathrm{D}$ levels and asthma attacks in children: Evaluation of the effects of combination therapy of atomization inhalation of budesonide, albuterol and vitamin D supplementation on asthmatic patients. Exp Ther Med. 2017;15(1):727-732.

20. Yadav M, Mittal K. Effect of vitamin D supplementation on moderate to severebronchial asthma. Indian J Pediatr. 2014;81(7):650-4.

Source of Support: Nil; Conflict of Interest: None

Submitted: 20-03-2019; Accepted: 12-04-2019; Published online: 16-05-2019 